\title{
Long-term outcomes after surgical repair of complete atrioventricular septal defect
}

\author{
Salil Ginde, MD, ${ }^{a}$ Janna Lam, BS, ${ }^{a}$ Garick D. Hill, MD, ${ }^{a}$ Scott Cohen, MD, ${ }^{b}$ Ronald K. Woods, MD, PhD,
} Michael E. Mitchell, MD, ${ }^{c}$ James S. Tweddell, MD, ${ }^{c}$ and Michael G. Earing, MD $^{\mathrm{a}, \mathrm{b}}$

\begin{abstract}
Objective: Survival after surgical repair for complete atrioventricular septal defect (CAVSD) has improved, but patients are at risk for reoperation to address left atrioventricular valve regurgitation and left ventricular outflow tract obstruction. We examined the long-term survival, need for reoperation, and associated risk factors after CAVSD repair at our institution.
\end{abstract}

Methods: Between 1974 and 2000, a total of 198 patients underwent surgical repair for CAVSD. Of these, 178 patients survived to hospital discharge, of whom $153(86 \%)$ had available follow-up data at a median postoperative time point of 17.2 years (range: 2 months to 38.1 years).

Results: Overall perioperative mortality was $10.1 \%$, with a significant decrease to $2.9 \%$ in the late surgical era: 1991 to $2000(P<.001)$. The overall estimated survival for the entire cohort was $85 \%$ at 10 years, $82 \%$ at 20 years, and $71 \%$ at 30 years after initial CAVSD repair. Requiring a reoperation after initial CAVSD repair was a risk factor for late mortality $(P=.04)$. The estimated freedom from reoperation was $88 \%$ at 10 years, $83 \%$ at 20 years, and $78 \%$ at 30 years after initial CAVSD repair. Indications for reoperation included left atrioventricular valve regurgitation in 14 patients $(7.1 \%)$ and left ventricular outflow obstruction in 7 patients $(3.5 \%)$.

Conclusions: Long-term survival after repair of CAVSD remains good. However, the need for reoperation is common and affects long-term survival after CAVSD repair. (J Thorac Cardiovasc Surg 2015;150:369-74)

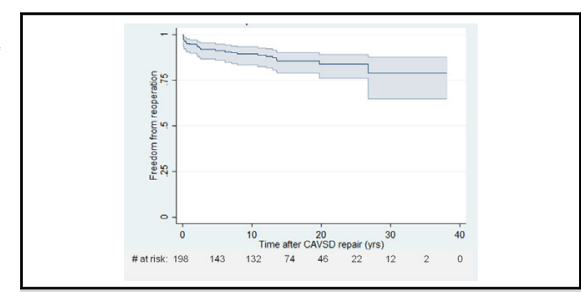

Estimated freedom from reoperation after CAVSD repair.

Central Message

Reoperation after surgical repair for complete atrioventricular septal defect affects long-term morbidity and mortality.

\section{Perspective}

With a median follow-up of $>17$ years after repair of complete atrioventricular septal defect, this study provides outcomes data, to assist providers in caring for this growing population who survive into adulthood. Although survival has improved, risk for reoperation remains. These findings can help providers determine the need for and frequency of cardiology follow-up and testing.

See Editorial Commentary page 375.
The first successful surgical repair of a complete atrioventricular septal defect (CAVSD) was performed by C. Walton Lillehei in $1955 .{ }^{1}$ Since that time, advances in surgical and medical management have resulted in decreased perioperative mortality and improved early survival. $^{2-4}$ Previous studies ${ }^{5,6}$ have demonstrated a 15-year survival of $86 \%$ to $89 \%$. However, despite improved survival, several single-center studies report that

\footnotetext{
From the Departments of ${ }^{\mathrm{a}}$ Pediatrics, ${ }^{\mathrm{b}}$ Internal Medicine, and ${ }^{\mathrm{c}}$ Cardiothoracic Surgery, Medical College of Wisconsin, Milwaukee, Wis.

Received for publication Dec 2, 2014; revisions received March 31, 2015; accepted for publication May 3, 2015; available ahead of print June 3, 2015

Address for reprints: Salil Ginde, MD, Department of Pediatrics, Medical College of Wisconsin, 9000 W Wisconsin Ave, MS 713, Milwaukee, WI 53226 (E-mail: sginde@chw.org).

$0022-5223 / \$ 36.00$

Copyright (c) 2015 by The American Association for Thoracic Surgery http://dx.doi.org/10.1016/j.jtcvs.2015.05.011
}

up to $10 \%$ of patients, after initial CAVSD repair, may require reoperation within 10 to 15 years, to address left atrioventricular (AV) valve regurgitation and left ventricular outflow tract obstruction. ${ }^{3,5-8}$ Given that survivors of CAVSD repair are now presenting to the Adult Congenital Heart Disease Program in their third and fourth decades of life, we sought to determine the long-term survival and need for reoperation in patients after CAVSD repair, at our institution.

\section{METHODS \\ Patient Population}

A total of 198 patients who had undergone complete surgical repair for CAVSD between the years 1974 and 2000 were identified from the Children's Hospital of Wisconsin surgical database. Patients with an associated diagnosis of tetralogy of Fallot, defined as subvalvular and/or valvular pulmonary stenosis that required intervention at the time of CAVSD repair, were excluded from this total. Patients with partial AV septal defect (ostium primum atrial septal defect), intermediate-type AV 


\section{Abbreviations and Acronyms \\ $\mathrm{AV}=$ atrioventricular \\ CAVSD $=$ complete atrioventricular septal defect}

septal defect (a common $\mathrm{AV}$ valve or 2 separate $\mathrm{AV}$ valve orifices, but restrictive or absent ventricular septal defect), or unbalanced forms of AV septal defect who underwent single-ventricle palliation were excluded. The protocol was approved by the Children's Hospital of Wisconsin Institutional Review Board.

\section{Surgical Era and Technique}

The 198 patients were divided into 2 groups, to determine the impact of surgical era on long-term outcomes. The early surgical era included those patients who underwent repair from 1974 to $1990(\mathrm{n}=93 ; 47 \%)$; the late surgical era included patients who underwent repair from 1991 to 2000 $(\mathrm{n}=105 ; 53 \%)$. Surgical repair of CAVSD was performed with either the classic 1-patch technique or the 2-patch technique, along with closure of the left AV valve cleft, as previously described. ${ }^{9}$ Briefly, the classic 1-patch technique was performed by dividing the common superior and inferior bridging leaflets, leaving slightly more tissue on the left side of the common AV valve. A single Dacron patch was sutured onto the right side of the ventricular septum, to close the septal defect, and the AV valve components were attached to the patch using felted mattress sutures, along with closure of the cleft of the left AV valve leaflet.

The 2-patch technique was performed by first closing the ventricular septal defect with a Dacron patch. The ventricular septal defect patch was positioned under the bridging leaflets and secured to the right side of the ventricular septum. Sutures were passed through the superior edge of the patch and through the bridging leaflets at the point of division between the right and left components of the common AV valve. These same sutures were passed through a second atrial septal defect patch and tied. The cleft of the newly constructed left AV valve was closed with interrupted sutures before completion of the atrial septal defect closure. Most patients in the early surgical era underwent repair with the classic 1-patch technique $(79.6 \%)$, compared with the 2-patch technique $(20.4 \%)$. In the late surgical era, most patients underwent the 2-patch technique $(98 \%)$ ). No patient underwent repair with the modified 1-patch technique.

\section{Study Endpoints}

Primary outcomes for the study included survival, and freedom from reoperation after initial CAVSD repair. Early death was defined as death within 30 days after CAVSD repair or before hospital discharge. Late death was defined as death beyond 30 days after CAVSD repair and after hospital discharge. Hospital survivor was defined as surviving beyond 30 days after CAVSD repair, and after hospital discharge. Reoperations included any cardiac surgery after CAVSD repair. Interventional cardiac catheterizations and permanent pacemaker placements performed during the study period were not included as reoperations but are discussed separately.

\section{Data Collection and Follow-up}

A retrospective analysis of medical records was performed for all 198 patients, to identify operative and long-term mortality and need for reoperation after CAVSD repair, as well as risk factors for mortality and reoperation, including surgical technique, surgical era, age at repair, and associated diagnoses. For the 178 hospital survivors, a total of 153 patients $(86.0 \%)$ had available and current data within the past 5 years that were obtained from either the medical record $(n=132)$ or a medical questionnaire that was sent to and returned by the patient's primary care physician inquiring about recent clinical status $(\mathrm{n}=21)$. The mean follow-up for hospital survivors was $17.42 \pm 7.8$ years $($ median $=17.2$ years; range $=2$ months to 38.1 years).

\section{Statistical Analysis}

Continuous variables are reported as mean $\pm \mathrm{SD}$, or median with range, and categoric variables are presented as frequencies and percentage of total. Groups were compared using $\chi^{2}$ analysis or the Fisher exact test for categoric variables and the Wilcoxon rank sum test for continuous variables. Cox proportional hazards models were used to evaluate the risk factors for mortality and need for reoperation. Risk factors for left $\mathrm{AV}$ valve reoperation and left ventricular outflow tract obstruction surgery were evaluated separately because these risks may occur at different time points. For these models, log transformation of age at initial repair was required, and interactions between variables were evaluated. Estimates of overall survival and freedom from late reoperation were calculated using the Kaplan-Meier method and compared, when necessary, using the log-rank test. Data were analyzed using StataIC 13 (Stata Corporation, College Station, Tex).

\section{RESULTS}

\section{Early Operative Patient Characteristics}

The patient characteristics for the 198 patients that underwent complete surgical repair for CAVSD are summarized in Table 1 . The mean age at the time of repair was $1.36 \pm 1.9$ years $($ median $=8.1$ months; range $=1$ month to 15 years). The mean age decreased, from 1.96 years in the early surgical era to 9.9 months in the late surgical era.

Associated diagnoses included Down syndrome in 156 patients $(78.8 \%)$, coarctation of aorta in $6(3.0 \%)$, and left ventricular outflow tract obstruction in $2(1.0 \%)$. A total of 32 patients $(16.2 \%)$ underwent palliation with a pulmonary artery band before complete repair of CAVSD.

\section{Mortality}

A total of 20 early operative deaths occurred, defined as death within 30 days after CAVSD repair or before hospital discharge, resulting in an overall early mortality of $10.1 \%$. The early mortality decreased significantly from $18.2 \%$ (17 of 93 patients) in the early surgical era to $2.9 \%$ (3 of 105 patients) in the late surgical era $(P<.001)$.

Among the 178 hospital survivors, 15 late deaths occurred after initial CAVSD repair. The cause of late death was cardiac related in 9 patients. Causes of cardiac-related deaths included: complications related to congestive heart failure in 1 patient who had a large residual ventricular septal defect who developed pneumonia and respiratory failure; 1 patient with severe left AV valve regurgitation who died in the postoperative period after left AV valve replacement at age 2 months; 1 patient with late diagnosis of coarctation of aorta who died in the postoperative period after surgical aortic arch repair; 2 patients with dilated cardiomyopathy of unknown etiology that may have been related to a history of complete heart block and/or the need for chronic ventricular pacing; and 3 patients with sudden death. The 3 patients with sudden deaths all had 
TABLE 1. Patient characteristics for 198 patients at the time of complete repair for complete atrioventricular septal defect repair

\begin{tabular}{lc}
\hline \multicolumn{1}{c}{ Characteristic } & Mean \pm SD or $\mathbf{n}(\%)$ \\
\hline Age at repair (y) & $1.36 \pm 1.90$ \\
Gender, female & $110(55.6)$ \\
Down syndrome & $156(78.8)$ \\
Associated congenital heart diagnoses & \\
Coarctation of aorta & $6(3.0)$ \\
LVOT obstruction & $2(1.0)$ \\
Early surgical era (1974-1990) & $93(47.0)$ \\
Age at repair (y) & $2.1 \pm 2.4$ \\
Classic 1-patch & 74 \\
2-patch & 19 \\
Late surgical era (1991-2000) & $105(53.0)$ \\
Age at repair (y) & $0.7 \pm 0.9$ \\
Classic 1-patch & 2 \\
2-patch & 103 \\
Prior pulmonary artery band & $32(16.2)$ \\
\hline
\end{tabular}

$S D$, Standard deviation; $L V O T$, left ventricular outflow tract.

less-than-severe left AV valve regurgitation, and no known residual cardiac defects at last follow-up. The causes of death were noncardiac or unknown in 6 patients.

The estimated overall survival for all CAVSD patients $(\mathrm{n}=198)$ was $85 \%$ at 10 years, $82 \%$ at 20 years, and $71 \%$ at 30 years after initial CAVSD repair (Figure 1). When early postoperative deaths were excluded, the estimated overall survival for the hospital survivors was $95 \%$ at 10 years, $92 \%$ at 20 years, and $80 \%$ at 30 years after initial CAVSD repair.

\section{Predictors of Late Mortality}

By univariate analysis, risk factors for late mortality included early surgical era, classic 1-patch surgical technique, older age at repair, and requiring a reoperation after initial CAVSD repair (Table 2). By multivariable analysis, only the need for reoperation was found to be a

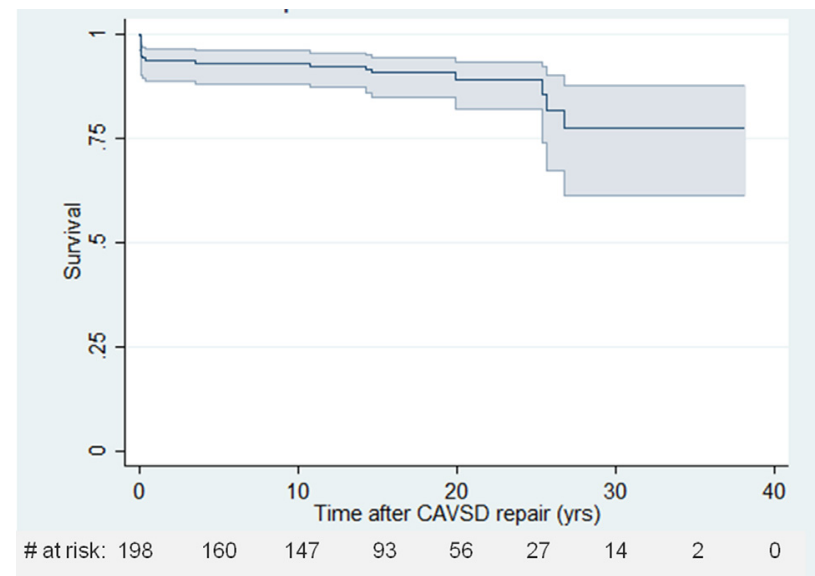

FIGURE 1. Estimated overall survival after CAVSD repair. CAVSD, Complete atrioventricular septal defect.
TABLE 2. Risk factors for late mortality, by univariate and multivariable proportional hazards analysis

\begin{tabular}{llclll}
\hline & \multicolumn{2}{c}{ Univariate analysis } & & \multicolumn{2}{c}{ Multivariable analysis } \\
\cline { 2 - 3 } \multicolumn{1}{c}{ Variable } & $\boldsymbol{P}$ value & HR $(\mathbf{9 5} \% \mathbf{C I})$ & & $\boldsymbol{P}$ value & HR $(\mathbf{9 5} \% \mathbf{C I})$ \\
\hline Early surgical era & .001 & $9.38(2.56-34.32)$ & .07 & $4.34(0.91-20.71)$ \\
Classic 1-patch & .0006 & $8.36(2.39-29)$ & .45 & $2.17(0.30-16)$ \\
$\begin{array}{l}\text { Older age at } \\
\quad \text { repair }\end{array}$ & .02 & NA & .42 & $1.01(0.96-1.02)$ \\
Required & & & & per y \\
$\quad$ reoperation & .007 & $5.4(1.77-16.6)$ & .04 & $3.06(1.05-8.91)$ \\
$\begin{array}{l}\text { Down syndrome } \\
\text { Prior PA band }\end{array}$ & .82 & $1.17(0.33-4.17)$ & .88 & $0.9(0.24-3.43)$ \\
\hline
\end{tabular}

$H R$, Hazard ratio; $C I$, confidence interval; $N A$, not applicable; $P A$, pulmonary artery.

significant risk factor for late mortality (hazard ratio 3.06; 95\% confidence interval: 1.05-8.91, $P=.04$ ). Early surgical era had a trend toward statistical significance $(P=.07)$, but other risk factors, including classic 1-patch technique, older age at repair, Down syndrome, and prior pulmonary artery band were not significant risk factors for late mortality.

\section{Reoperations}

A total of 26 patients (of 198) required $\geq 1$ reoperation after initial CAVSD repair. Six patients $(3 \%)$ required an early reoperation, within 30 days or before hospital discharge, after CAVSD repair, and all 6 survived to hospital discharge. Early reoperations included 3 for left AV valve regurgitation, 2 for residual ventricular septal defect, and 1 for both residual ventricular septal defect and left $\mathrm{AV}$ valve regurgitation. Of the hospital survivors $(\mathrm{n}=178), 21(11.8 \%)$ required $\geq 1$ late reoperation after initial CAVSD repair.

The overall estimated freedom from reoperation for the entire cohort $(\mathrm{n}=198)$ after CAVSD repair was $88 \%$ at 10 years, $83 \%$ at 20 years, and $78 \%$ at 30 years

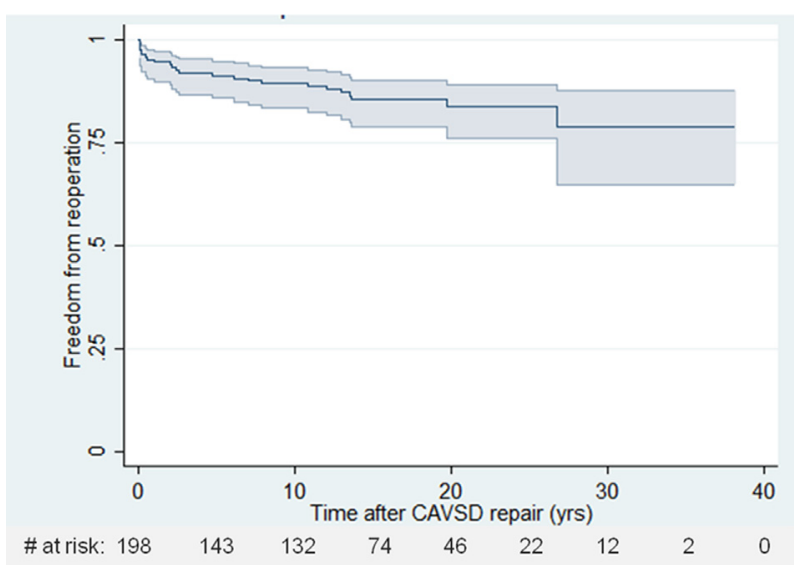

FIGURE 2. Estimated freedom from reoperation after CAVSD repair. CAVSD, Complete atrioventricular septal defect. 
TABLE 3. Type and frequency of reoperations performed after complete AV septal defect repair $(n=198)$

\begin{tabular}{lr}
\hline \multicolumn{1}{c}{ Indication for reoperation } & $\mathbf{N}(\%)$ \\
\hline Left AV valve regurgitation & $14(7.1)$ \\
LVOT obstruction & $7(3.5)$ \\
Residual VSD & $7(3.5)$ \\
Residual ASD & $1(0.5)$ \\
Native coarctation of the aorta (surgical repair) & $1(0.5)$ \\
Vascular ring & $1(0.5)$ \\
\hline
\end{tabular}

$A V$, Atrioventricular; $L V O T$, left ventricular outflow tract; $V S D$, ventricular septal defect; $A S D$, atrial septal defect.

(Figure 2). Table 3 summarizes the indications for reoperation for all 198 patients after CAVSD repair.

The most common indication for reoperation was for left $\mathrm{AV}$ valve regurgitation in 14 patients $(7.1 \%)$, which was performed at a median postoperative follow-up of 1.1 years (range $=1$ day to 19.7 years) after initial CAVSD repair. The overall estimated freedom from reoperation for left AV valve regurgitation was $93 \%$ at 10 years, $89 \%$ at 20 years, and $89 \%$ at 30 years. Of the 14 patients, 12 underwent valve repair, and 2 underwent valve replacement with a mechanical prosthesis. Repair of the valve consisted of isolated closure of the residual cleft in 6 , and a combination of annuloplasty and cleft closure in 6 .

Two of the 14 patients required a second reoperation on the left AV valve. One of the second reoperations was performed for persistent valve insufficiency 1 month after attempted cleft closure during the first reoperation; the patient was subsequently found to have a tear in the inferior bridging leaflet of the left AV valve. The tear was repaired, resulting in mild valve insufficiency at last follow-up. The other second reoperation was performed in a patient that required re-replacement of a mechanical valve 5 years after the first reoperation. Only 1 postoperative death after left AV valve surgery occurred, in a patient aged 2 months who underwent valve replacement.

Repair of left ventricular outflow tract obstruction was performed in 7 patients $(3.5 \%)$ at a median postoperative follow-up of 6.2 years (range $=2.2$ months to 13.5 years)

TABLE 4. Risk factors for reoperation, by univariate and multivariable proportional hazards analysis

\begin{tabular}{|c|c|c|c|c|}
\hline \multirow[b]{2}{*}{ Variable } & \multicolumn{2}{|c|}{ Univariate analysis } & \multicolumn{2}{|c|}{ Multivariable analysis } \\
\hline & $P$ value & HR $(95 \%$ CI $)$ & $P$ value & HR $(95 \%$ CI $)$ \\
\hline Early surgical era & .04 & $2.45(1.06-5.67)$ & .74 & $1.29(0.29-5.62)$ \\
\hline Older age at repair & .0001 & NA & .6 & $1.0(0.97-1.01)$ \\
\hline Classic 1-patch & .002 & $3.8(1.63-8.88)$ & .003 & $3.71(1.56-8.78)$ \\
\hline $\begin{array}{l}\text { Non-Down } \\
\text { syndrome }\end{array}$ & .1 & $2.15(0.87-5.39)$ & .27 & $1.62(0.68-3.84)$ \\
\hline $\begin{array}{c}\text { Coarctation } \\
\text { of aorta }\end{array}$ & .16 & $4.14(0-22)$ & .47 & $2.09(0.28-15.53)$ \\
\hline Prior PA band & .17 & $0.51(0.2-1.31)$ & .7 & $0.81(0.28-2.33)$ \\
\hline
\end{tabular}

$H R$, Hazard ratio; $C I$, confidence interval; $N A$, not applicable; $P A$, pulmonary artery.
TABLE 5. Risk factors for need for a reoperation to address left atrioventricular valve regurgitation, by univariate and multivariable proportional hazards analysis

\begin{tabular}{lccccc}
\hline & \multicolumn{2}{c}{ Univariate analysis } & & \multicolumn{2}{c}{ Multivariable analysis } \\
\cline { 2 - 3 } \cline { 5 - 6 } \multicolumn{1}{c}{ Variable } & $\boldsymbol{P}$ value & HR $(\mathbf{9 5} \% \mathbf{C I})$ & & $\boldsymbol{P}$ value & HR $(\mathbf{9 5} \% \mathbf{C I})$ \\
\hline Early surgical era & .79 & $1.32(0.48-3.65)$ & .70 & $1.45(0.22-9.51)$ \\
Older age at repair & .81 & NA & .26 & $0.97(0.93-1.02)$ \\
Classic 1-patch & .17 & $1.93(0.70-5.37)$ & .11 & $2.39(0.82-6.98)$ \\
$\begin{array}{l}\text { Non-Down } \\
\quad \text { syndrome }\end{array}$ & .32 & $1.97(0.67-5.89)$ & .24 & $1.96(0.65-5.95)$ \\
$\begin{array}{l}\text { Coarctation } \\
\quad \text { of aorta }\end{array}$ & .07 & $6.89(0-35.96)$ & .29 & $3.06(0.39-23.72)$ \\
Prior PA band & .07 & $2.89(0.96-8.78)$ & .49 & $1.57(0.44-5.58)$ \\
\hline
\end{tabular}

$H R$, Hazard ratio; $C I$, confidence interval; $N A$, not applicable; $P A$, pulmonary artery.

after initial CAVSD repair. The overall estimated freedom from reoperation for left ventricular outflow tract obstruction was $97 \%$ at 10 years, $94 \%$ at 20 years, and $94 \%$ at 30 years. These repairs consisted of resection of a discrete subaortic fibromuscular membrane in 4 patients, resection of a subaortic membrane and secondary left AV valve chordae in 2 , and repair of left ventricular outflow tract obstruction associated with a mechanical left $\mathrm{AV}$ valve in 1 patient. Two patients required a second reoperation for left ventricular outflow tract obstruction, both for resection of a recurrent subaortic membrane at 6 and 11 years after the first reoperation, and both patients have less-than-mild residual outflow tract obstruction at last follow-up.

Residual ventricular septal defect was an indication for reoperation in 7 patients $(3.5 \%), 6$ of whom had undergone repair with the classic 1-patch technique. The remaining reoperations were performed for: residual atrial septal defect in 1 patient $(0.5 \%)$; native coarctation of the aorta in $1(0.5 \%)$; and vascular ring in $1(0.5 \%)$.

Interventional catheterization was performed in 3 patients for balloon angioplasty of recurrent coarctation of the aorta. Permanent pacemakers were placed in 7 patients $(3.5 \%)$ for postoperative complete heart block, of which 4 were placed during the early postoperative period, and 3

TABLE 6. Risk factors for need for a reoperation to address left ventricular outflow tract obstruction, by univariate and multivariable proportional hazards analysis

\begin{tabular}{|c|c|c|c|c|}
\hline \multirow[b]{2}{*}{ Variable } & \multicolumn{2}{|c|}{ Univariate analysis } & \multicolumn{2}{|c|}{ Multivariable analysis } \\
\hline & $P$ value & HR $(95 \%$ CI $)$ & $P$ value & HR $(95 \%$ CI $)$ \\
\hline Early surgical era & .15 & $3.55(0.76-16.5)$ & .8 & $1.36(0.13-14.49)$ \\
\hline Older age at repair & .38 & NA & .27 & $0.97(0.91-1.03)$ \\
\hline Classic 1-patch & .05 & $5.14(1.17-22.6)$ & .10 & $6.17(1.24-68.59)$ \\
\hline $\begin{array}{l}\text { Non-Down } \\
\text { syndrome }\end{array}$ & .37 & $2.32(0.59-9.24)$ & .43 & $1.81(0.42-7.72)$ \\
\hline $\begin{array}{l}\text { Coarctation } \\
\text { of aorta }\end{array}$ & $>.98$ & $0(0-16.22)$ & $>.98$ & $0(0-\infty)$ \\
\hline Prior PA band & $>.98$ & $0.73(0-4.8)$ & .55 & $0.52(0.06-4.44)$ \\
\hline
\end{tabular}


were placed for late presentation of complete heart block at 13,17 , and 19 years after initial CAVSD repair.

\section{Predictors for Reoperation}

By univariate analysis, risk factors for reoperation included early surgical era, older age at repair, and classic 1-patch surgical technique (Table 4). By multivariable analysis, classic 1-patch technique was a significant risk factor for reoperation (hazard ratio: $3.71 ; 95 \%$ confidence interval: 1.56-8.78). However, no risk factors were found to predict the need for repair of left $\mathrm{AV}$ valve regurgitation (Table 5) or left ventricular outflow tract obstruction (Table 6).

\section{DISCUSSION}

This study sought to identify the long-term survival and risk for reoperation in 198 patients after CAVSD repair at our institution from 1974 to 2000 . The overall survival for the cohort was $82 \%$ at 20 years, and $71 \%$ at 30 -year follow-up after initial CAVSD repair. The estimated survival for patients that survived to hospital discharge after initial CAVSD repair was $92 \%$ at 20 years and $80 \%$ at 30 years after repair.

The only significant risk factor for late mortality was need for a reoperation after initial CAVSD repair. Most of the late deaths were found to be cardiac related, and many could be directly attributed to complications from residual cardiac lesions or from postoperative complications after reoperation for residual cardiac lesions. Early surgical era was associated with higher early postoperative mortality, but additionally, showed a trend as a significant risk factor for late mortality. The same improvements in preoperative management that have reduced operative mortality for patients in the later surgical era, including techniques of cardiopulmonary bypass, myocardial protection, anesthesia, and postoperative management, may, in addition, reduce the risk for myocardial insults that can contribute to the development of arrhythmias and/or cardiac dysfunction in long-term follow-up.

Pulmonary arterial hypertension may have additionally contributed to risk for late mortality: Patients repaired in the early surgical era were older at time of the repair and thus more likely to have developed persistent pulmonary vascular obstructive disease. ${ }^{10}$ Older age at repair, however, was not a significant risk factor for mortality in our study, and measures of pulmonary artery pressures, either with invasive or noninvasive methods, were not consistently available to evaluate this as a risk factor.

In addition, this study demonstrated that the freedom from reoperation was $83 \%$ at 20 years, and $78 \%$ at 30 years follow-up, after initial CAVSD repair at our institution. Surgery for left AV valve regurgitation was the most common indication for reoperation during long-term follow-up and was performed in $7.1 \%$ of the study population. This percentage is similar to previously published single-center series, demonstrating reoperation for left $\mathrm{AV}$ valve regurgitation in $8.7 \%$ to $12 \%$ of patients at up to 15 years after CAVSD repair. ${ }^{5-8}$

Most left AV valve surgeries in the current study occurred relatively early, at a median postoperative follow-up of 1.1 years, and no patient required primary reoperation on the valve after 19.7 years. Rhodes and colleagues ${ }^{11}$ demonstrated that progression of left $\mathrm{AV}$ valve regurgitation and subsequent need for reoperation is a relatively early complication after CAVSD repair. Our study additionally demonstrates that primary reoperation for left $\mathrm{AV}$ valve regurgitation can usually be accomplished with repair, rather than with replacement of the valve, which is consistent with other single-center patient series. ${ }^{12-14}$ Reoperation for left ventricular outflow tract obstruction was required in $3.5 \%$ of patients. The predominant mechanism for obstruction was an acquired discrete subaortic membrane, a finding similar to those reported by previous single-center studies of patients after CAVSD repair. ${ }^{15,16}$

Multivariable analysis identified the classic 1-patch technique as a risk factor for reoperation after CAVSD repair. This risk was largely due to reoperation for residual ventricular septal defects; 6 of the 7 patients that underwent such reoperation had undergone the classic 1-patch repair. The risk for patch dehiscence and residual ventricular septal defects after the classic 1-patch technique for CAVSD repair has been described previously. ${ }^{4,17}$ The risk seems to be lower after 2-patch repair. ${ }^{18,19}$ However, a more recent multicenter cohort of patients with CAVSD did not demonstrate a higher risk for residual ventricular septal defect in patients repaired with the classic 1-patch versus the 2-patch technique. ${ }^{20}$ In addition, the classic 1-patch technique involves dividing the common valve leaflets and suspending them from a single patch; it may result in more distortion of the valve tissue, with a higher risk for reoperation for left $\mathrm{AV}$ valve regurgitation. ${ }^{4}$ However, patch technique was not found to be a significant risk factor for this complication in our series. In addition, patch technique was not a risk factor for reoperation for left ventricular outflow tract obstruction.

\section{Limitations}

Although this study includes a large cohort of patients who underwent surgical repair of CAVSD, it has several limitations. It is a retrospective study, over a long study period at a single tertiary care center, with variable and incomplete follow-up among patients. All patients underwent surgical repair at Children's Hospital of Wisconsin, mostly with 1 of 2 cardiovascular surgeons, and outcomes may not account for variations in surgical techniques and postoperative management at other institutions. Diagnostic studies at the time of initial CAVSD 
repair were not available for all patients and therefore could not be included in the analysis for long-term outcomes. Finally, although this study focused on mortality and reoperation, data on functional status, quality of life, arrhythmias, and other important late clinical outcomes were not available on all late survivors.

\section{CONCLUSIONS}

Overall survival after CAVSD repair remains good in long-term follow-up. However, consistent with previous studies, patients are at risk for reoperation, particularly to address left AV valve regurgitation and left ventricular outflow tract obstruction. Furthermore, the need for reoperation affects late survival after CAVSD repair. The continued risk for long-term complications requires ongoing care and follow-up, by pediatric and adult congenital cardiologists, for this growing population of survivors.

\section{Conflict of Interest Statement}

SG, JL, GDH, SC, RKW, and MGE have nothing to disclose with regard to commercial support. MEM has ownership interest/partnership in Ariosa Diagnostics, Tai Diagnostics, and MD Interactive. JST is a consultant and speaker for CorMatrix. All other authors have nothing to disclose with regard to commercial support.

\section{References}

1. Lillehei CW, Cohen M, Warden HE, Varco RL. The direct-vision intracardiac correction of congenital anomalies by controlled cross circulation; results in thirty-two patients with ventricular septal defects, tetralogy of Fallot, and atrioventricularis communis defects. Surgery. 1955;38:11-29.

2. Bando K, Turrentine MW, Sun K, Sharp TG, Ensing GJ, Miller AP, et al. Surgical management of complete atrioventricular septal defects. A twenty-year experience. J Thorac Cardiovasc Surg. 1995;110:1543-52.

3. Tweddell JS, Litwin SB, Berger S, Friedberg DZ, Thomas JP, Frommelt PC, et al. Twenty-year experience with repair of complete atrioventricular septal defects. Ann Thorac Surg. 1996;62:419-24.

4. Hanley FL, Fenton KN, Jonas RA, Mayer JE, Cook NR, Wernovsky G, et al. Surgical repair of complete atrioventricular canal defects in infancy. Twenty-year trends. J Thorac Cardiovasc Surg. 1993;106:387-94.

5. Crawford FA Jr, Stroud MR. Surgical repair of complete atrioventricular septal defect. Ann Thorac Surg. 2001;72:1621-8.
6. Hoohenkerk GJ, Bruggemans EF, Rijlaarsdam M, Schoof PH, Koolbergen DR, Hazekamp MG. More than 30 years' experience with surgical correction of atrioventricular septal defects. Ann Thorac Surg. 2010; 90:1554-61.

7. Gunther T, Mazzitelli D, Haehnel CJ, Holper K, Sebening F, Meisner H. Long-term results after repair of complete atrioventricular septal defects: analysis of risk factors. Ann Thorac Surg. 1998;65:754-9.

8. Boening A, Scheewe J, Heine K, Hedderich J, Regensburger D, Kramer HH, et al. Long-term results after surgical correction of atrioventricular septal defects. Eur J Cardiothorac Surg. 2002;22:167-73.

9. Litwin SB. Endocardial cushion defects. In: Litwin S, ed. Color Atlas of Congenital Heart Surgery. 2nd ed. New York: Springer; 2007.

10. Newfeld EA, Sher M, Paul MH, Nikaidoh H. Pulmonary vascular disease in complete atrioventricular canal defect. Am J Cardiol. 1977;39:721-6.

11. Rhodes J, Warner KG, Fulton DR, Romero BA, Schmid CH, Marx GR. Fate of mitral regurgitation following repair of atrioventricular septal defect. Am J Cardiol. 1997;80:1194-7.

12. Malhotra SP, Lacour-Gayet F, Mitchell MB, Clarke DR, Dines ML, Campbell DN. Reoperation for left atrioventricular valve regurgitation after atrioventricular septal defect repair. Ann Thorac Surg. 2008;86:147-51.

13. Hoohenkerk GJ, Bruggemans EF, Koolbergen DR, Rijlaarsdam ME, Hazekamp MG. Long-term results of reoperation for left atrioventricular valve regurgitation after correction of atrioventricular septal defects. Ann Thorac Surg. 2012;93:849-55.

14. Pontailler M, Kalfa D, Garcia E, Ly M, Le Bret E, Roussin R, et al. Reoperations for left atrioventricular valve dysfunction after repair of atrioventricular septal defect. Eur J Cardiothorac Surg. 2014;45:557-62.

15. Van Arsdell GS, Williams WG, Boutin C, Trusler GA, Coles JG, Rebeyka IM, et al. Subaortic stenosis in the spectrum of atrioventricular septal defects. Solutions may be complex and palliative. J Thorac Cardiovasc Surg. 1995; 110:1534-41.

16. Stulak JM, Burkhart HM, Dearani JA. Reoperations after repair of partial and complete atrioventricular septal defect. World J Pediatr Congenit Heart Surg. 2010;1:97-104.

17. Capouya ER, Laks H, Drinkwater DC Jr, Pearl JM, Milgalter E. Management of the left atrioventricular valve in the repair of complete atrioventricular septal defects. J Thorac Cardiovasc Surg. 1992;104:196-201.

18. Litwin SB, Tweddell JS, Mitchell ME, Mussatto KA. The double patch repair for complete atrioventricularis communis. Sem Thorac Cardiovasc Surg Pediatr Card Surg Annu. 2007;10:21-7.

19. Backer CL, Mavroudis C, Alboliras ET, Zales VR. Repair of complete atrioventricular canal defects: results with the two-patch technique. Ann Thorac Surg. 1995;60:530-7.

20. Atz AM, Hawkins JA, Lu M, Cohen MS, Colan SD, Jaggers J, et al. Surgical management of complete atrioventricular septal defect: associations with surgical technique, age, and trisomy 21. J Thorac Cardiovasc Surg. 2011;141: $1371-9$.

Key Words: Atrioventricular septal defect, endocardial cushion defect, mitral insufficiency, subaortic stenosis, adult congenital heart disease 